Glover, J., Liebling, H., Barrett, H., \& Goodman, S. (2017). The psychological

and social impact of female genital mutilation: A holistic conceptual framework.

Journal of International Studies, 10(2), 219-238. doi:10.14254/2071-8330.2017/10-

$2 / 16$

\title{
The psychological and social impact of female genital mutilation: A holistic conceptual framework
}

\author{
Jennifer Glover \\ Universities of Coventry and Warwick, \\ $U K$ \\ Email:jennifer@jennifer-glover.co.uk
}

\section{Helen Liebling}

Coventry University,

$U K$

Email:bsx497@coventry.ac.uk

\author{
Hazel Barrett \\ Coventry University, \\ UK \\ Email:gex037@coventry.ac.uk
}

\author{
Simon Goodman \\ Coventry University, \\ UK \\ Email:aa4592@coventry.ac.uk.
}

Abstract. Objectives: The current research aimed to gain an understanding of women's experiences of FGM to develop an evidence based holistic conceptual framework for professionals dealing with the impact of FGM and responses required for survivors and their children. Method: Using a grounded theory approach, qualitative semi-structured interviews were carried out with 20 women survivors of FGM. Results: Participant's related culture, religion, role of men, lack of education, female identity and deception as the major factors influencing their understanding and the impact of FGM. Their experiences of FGM, as well as being influenced by their conceptualisation of the practice, led to effects on their emotional life, relationships, identity, and physical body. The fear resulting from FGM that women described affected their ability to enhance their resilience. All the core categories of emotional, relational, identity, and physical impact, as well as resilience, were further influenced by the key stages of womanhood; including menstruation, marriage and childbirth. Women voiced their views that all the above issues were compounded by their needs not being met and the lack of meaningful and effective service responses. Conclusions: There are complex systems and relationships that influence the psychological and social impact of 
FGM. These have core implications for clinical and policy in relation to maternity and healthcare services.

Keywords: female genital mutilation, grounded theory, resilience, framework, Africa.

JEL Classification: I19, Z19

\section{INTRODUCTION}

This paper proposes that a holistic conceptual framework should be adopted by health professionals when dealing with survivors of FGM. Having undertaken a grounded theory study with FGM survivors living in the UK, focussing on the psychological and social impact of FGM, it became clear that the psychological impact of FGM could not be dealt with without consideration of the physical impact of the procedure and the cultural context of the practice. The research demonstrated that by treating the physical and psychological impact of FGM separately, as is often the case in the NHS, and without consideration of the cultural context and the stage in the life cycle of the survivor, many survivors' resilience to live with FGM was undermined.

Female Genital Mutilation (FGM) "comprises all procedures that involve partial or total removal of the external female genitalia, or other injury to the female genital organs for non-medical reasons" (WHO, 2016, p. 1). An estimated 200 million girls and women globally have undergone FGM (UNICEF, 2016). Although practised worldwide, it is most prevalent in 30 African, Middle Eastern and South-East Asian countries. It is estimated that as a result of international migration, 60,000 girls born to mothers with FGM are now living in the UK (Macfarlane \& Dorkenoo, 2015) with 20,000 girls at risk of being 'cut' (Yoder et al., 2004). Research has suggested that the physical health complications that can arise from FGM also lead to psychological effects (Lockhat, 2004), however despite being treated within the National Health Service (NHS) system, there are few services for psychological support and little recognition of the links between the psychological and physical impact of FGM. This has particular implications for health care professionals dealing with survivors of FGM (Girls Summit, 2014; Global Summit to End Sexual Violence in Conflict, 2014).

Despite research evidencing the influence of childhood trauma on later psychological well-being, (Bebbington et al., 2011; Read et al., 2003) empirical research investigating the psychological impact of FGM is limited, and rarely given the policy and practice consideration that it requires. Whilst many articles reference the concept of 'emotional and psychological' difficulties, (Mulongo, Martin, \& McAndrew, 2014) this is rarely substantiated with empirical evidence and studies that do exist tend to apply a western Post Traumatic Stress Disorder (PTSD) framework to responses of survivors. This fits poorly with the local cosmologies, norms, and values within which survivors make sense of their experiences (Boyden \& Gibbs, 1997; Liebling-Kalifani, 2010; Levine, 1999; Wessells, 1999). Due to the emphasis on the physical consequences of FGM, and the neglect of the psychological impact, it is important to create further understanding of the effects and meaning of FGM from the perspective of survivors themselves.

Previous research with survivors of sexual and gender-based violence has found that medicalising women's distress fails to adequately highlight women's own gendered and collective experiences of FGM within its cultural context and neglects survivors' resilience (Burstow, 2005; Liebling-Kalifani, 2009; 2010). Placing greater emphasis on culturally-sensitive frameworks provides a starting point that recognises women's own capacities to deal with their experiences.

The majority of published research with FGM survivors has tended to be diagnostically driven and lacking sufficient attention to gendered frameworks (Berg et al., 2010). Furthermore, women are rarely given the opportunity to voice their views and perceptions regarding the impact of FGM on their lives. Thus there 
is a need for a holistic conceptual framework incorporating physical, psychological, social-cultural influences and women's life course experiences. This research aimed to fill this gap and investigate the experiences of women who had undergone FGM and the psychological effects they had experienced. It also sought to understand the psychological impact of physical health complications, survivor's resilience and their cultural context by addressing the following questions:

- What are survivor's experiences of Female Genital Mutilation?

- What are survivor's understandings of the impact of their experiences?

- How do survivors deal with the impact of their experiences?

This paper presents empirical research undertaken, where in-depth interviews were carried out with adult survivors of FGM. The analysis indicated a highly complex and often culturally- driven relationship between the physical and mental impacts of FGM on these women. The grounded approach facilitated the development of a holistic conceptual framework for understanding the psychological impact of FGM that is of relevance to both practitioners and policy makers.

\section{METHOD}

A grounded theory qualitative methodology was adopted to provide analysis of in-depth, existential accounts of women's views and experiences of the psychological impact of FGM. This allowed for the development of a conceptual framework arising from women's own narratives. As the research focussed on women's experiences of FGM, principles of feminist research were observed ensuring a non-hierarchical relationship between researcher and participant, empowerment of the participant, and a reciprocal research process. Further in line with a feminist approach, a reflexive stance towards the research process and analysis was used where the researcher acknowledged the role of their own positionality, presuppositions and interpreted data contextually within time, place, culture, and situation (Bryant \& Charmaz, 2007). To ensure the reliability and credibility of the research (Mays \& Pope, 2000), theoretical memos were kept to ensure the theory was grounded in the data. Validity checks were carried out between the authors. In addition, where prior consent had been granted, participants were invited to validate the emergent themes of their transcripts.

The research was designed and conducted in accordance with the British Psychological Society's (2010) ethical guidelines and ethical approval was granted from Coventry University Ethics Committee. All identifiable information was removed and each participant was allocated a pseudonym to protect their confidentiality.

Due to the sensitive nature of FGM a non-probability convenience sampling frame based on snowballing was implemented. All women who participated had experienced FGM, were over the age of 18, were from African practising groups, resided in the UK, and provided informed consent. Twenty participants were recruited including women from Somalia $(\mathrm{n}=10)$, Kenya $(\mathrm{n}=2)$, South Africa $(\mathrm{n}=6)$, and The Gambia $(\mathrm{n}=2)$. Eight women identified themselves as being Roman Catholic and twelve women identified themselves as being Muslim. The mean age of participants was 38 years $(\mathrm{SD}=6.5$, range $=25-51)$. The average length of time living in the UK was 12.5 years.

Participants were recruited through advertisements placed in UK refugee centres and non-government organisations (NGO) working with survivors of FGM. Prior to being interviewed, information sheets were provided and written consent was obtained. All interviews were audio-recorded and ranged from 25 to 127 minutes in length. Upon completion of each interview, a verbal debriefing was provided by the researcher and participants were signposted to support services if required. Interviews were transcribed verbatim and analysed concurrently with data collection in line with grounded theory procedure (Strauss \& Corbin, 1998). 
Using NVivo software, 373 open codes and 38 axial codes were identified. Selective coding identified nine core categories thereby leading to the development of the framework presented in Figure 1.

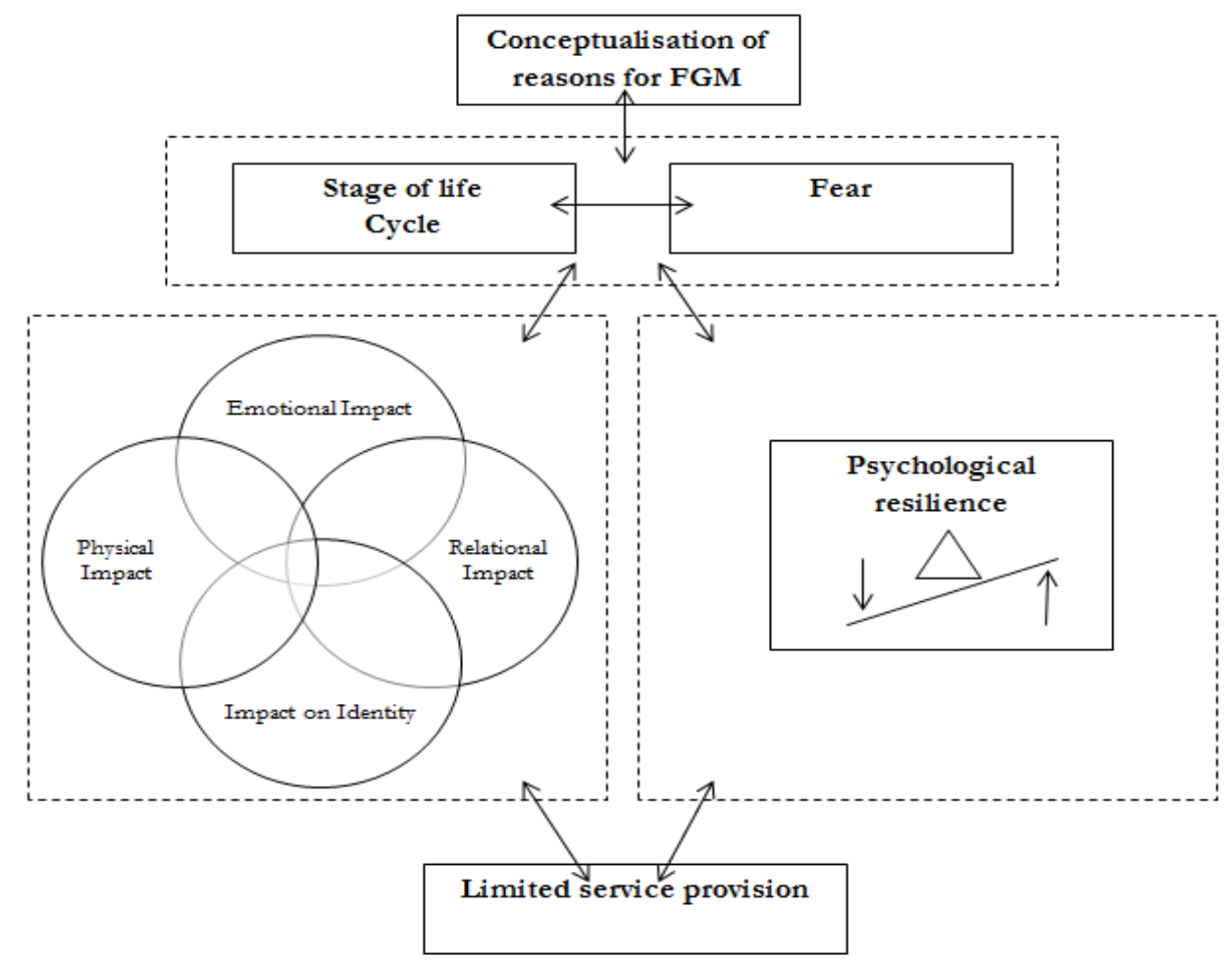

Figure 1. Holistic conceptual framework of the psychological impact of female genital mutilation Source: own compilation

As shown in Figure 1, the resulting holistic conceptual framework, which encapsulates nine core categories, shows how the psychological impact of FGM is multifaceted and complex. Participants related several major factors as influencing their conceptualisation of the reasons for FGM, each of which reciprocally impacted upon their emotional life, relationships, identity, and physical body. The fear that women described resulting from FGM affected their ability to enhance their resilience and interacted with the core categories of emotional, relational, identity, and physical impact, as well as resilience. All of these concepts were also influenced by key stages of womanhood including menstruation, marriage and childbirth. These aspects were further compounded by ongoing unmet health needs and the lack of effective service responses.

Each core category contains several axial codes. A summary of each axial code, along with verbatim quotations that illustrate the codes is provided in Tables 1-9 below. The paper will provide an overview of the core categories, their generation, and relationship to one another showing how the holistic conceptual framework was developed.

\section{Conceptualisation of reasons for FGM}

Women identified differing reasons given to them as an infant regarding the reasons for them having FGM. Based on women's narratives, it was conveyed that their conceptualisation of the reasons for the practice including; lack of knowledge, religion, the role of men, cultural pressure, female identity, and deception were closely related in terms of analysis, and were hence categorised together within the 
conceptual framework. Furthermore, the reasons given for the practice of FGM appeared to shape women's subsequent resilience and other impacts therefore the positioning of this facet at the top of the model represents this. Table 1 contains verbatim quotes which illustrate each axial code.

Table 1

Quotes illustrating the Coding for the 'Conceptualisation of reasons for FGM'

\begin{tabular}{|c|c|c|}
\hline $\begin{array}{l}\text { Conceptual } \\
\text { code }\end{array}$ & $\begin{array}{l}\text { Axial } \\
\text { code }\end{array}$ & Verbatim Quotations \\
\hline \multirow{6}{*}{$\begin{array}{l}\text { Understanding } \\
\text { of FGM }\end{array}$} & $\begin{array}{l}\text { Lack of } \\
\text { knowledge }\end{array}$ & $\begin{array}{l}\text { 'My mother passed away } 2 \text { years ago and to her dying day she apologised for a lot } \\
\text { of mistakes that she made when raising us but she never apologised for doing } \\
\text { FGM to me because she never saw anything wrong with it she thought I } \\
\text { circumcise your younger brother and I circumcise you what's the difference'. } \\
\text { (Faridah Lines 73-75) } \\
\text { '... if they educated, knew about the pain after that then they wouldn't do it because } \\
\text { they didn't have any knowledge ... culturally if they were educated they might have } \\
\text { said no don't have it'. } \\
\text { (Zahara Lines 274-276) }\end{array}$ \\
\hline & Religion & $\begin{array}{l}\text { 'In a weird way I blame religion, I know today we say nothing to do with it, but } \\
\text { religion it never stopped it and people let it happen in the name of Allah. I love } \\
\text { my religion, but it's a disgrace that it was used as a reason'. (Ebony, Lines } 82-84 \text { ) } \\
\text { '... they are using religion as a scapegoat but in the Holy Koran it doesn't say it at } \\
\text { all, so this is culture, its nothing to do with Islam'. (P10, Fabia, Lines } 225 \text { - 226) } \\
\text { '...when I grew up and I learn and get educated and I make the research with the } \\
\text { Muslim people and I see it ... there's no way I can see where religion says about it'. } \\
\text { (Sabina, Lines 267-269) }\end{array}$ \\
\hline & $\begin{array}{l}\text { Role of } \\
\text { men }\end{array}$ & $\begin{array}{l}\text { 'No-one is going to be married because a husband he maybe say you didn't have } \\
\text { FGM so you have no future, nothing, so that's another pressure, we have to have } \\
\text { it.' Jamina, Lines } 143-144 \text { ) } \\
\text { '... Back home I think the reason they were doing it is for the man's sake, people } \\
\text { were believing that without FGM the girl wouldn't be a virgin and couldn't get } \\
\text { married as the man would reject her'. (Fabia, Lines } 250-151 \text { ) }\end{array}$ \\
\hline & $\begin{array}{l}\text { Cultural } \\
\text { pressure }\end{array}$ & $\begin{array}{l}\text { 'Yea its only cultural and they believe we have to have it because the things is we } \\
\text { did we done for a long time so in their mind they say we have to have it ... why are } \\
\text { we stopping ... because of our Grandma, or grandpa, we have culture'. (Jamina, } \\
\text { 185-187) } \\
\text { 'I was young so that's why she didn't want me to have it ... but culture was pushing } \\
\text { her to have it'. (Saleema, Lines } 81 \text { ) } \\
\text { I'm angry because of the culture, they believe you have to have it, so I don't blame } \\
\text { anyone but I do blame culture when I hear it, it makes me angry, why do they do } \\
\text { these things to me'. (Zahara, Lines } 261-263 \text { ) }\end{array}$ \\
\hline & $\begin{array}{l}\text { Female } \\
\text { Identity }\end{array}$ & $\begin{array}{l}\text { 'It's just the whole reality of just being a woman what I had to go through just for } \\
\text { the fact I am a woman you know'. (Faridah, Lines 230-331) } \\
\text { 'For me it seemed to be normal because all the ladies they have to go through this } \\
\text { stage, they have to pass this stage [yeah] they have to go just through it because } \\
\text { they are a woman. (Sabina, Lines } 242-243 \text { ) }\end{array}$ \\
\hline & Deception & $\begin{array}{l}\text { No, no permission forms or nothing, you go with your friends or with the } \\
\text { neighbours, that's it. (Jamina, Lines 138) } \\
\text { 'Dad was stronger than Mum, he knew I need FGM or wouldn't get married. He } \\
\text { didn't need my Mum permission so he didn't it without her. (Ebony, Lines 88-89) }\end{array}$ \\
\hline
\end{tabular}

Source: own research

Participants expressed the view that had their parents, specifically their mothers been aware of the harmful physical and emotional impact of FGM then they believed they would not have continued the practice. Perceiving FGM as being practised due to lack of knowledge indirectly influenced the relational 
and emotional impact; for some participants conceptualising FGM as being due to lack of knowledge, ameliorated anger towards their mother, however for other women it served to increase these emotions thereby negatively impacting upon the mother-daughter relationship.

Lack of knowledge also related to participant's understanding of the role of religion in continuing the practice. Women identified that FGM was regularly attributed by practising communities as being a religious necessity and that not to have FGM would be to go against religion. All the women interviewed admitted that as adults they later realised that FGM had 'nothing to do with religion'. Analysis revealed that this conceptualisation of FGM related to women's resilience, with many women expressing a duty towards educating others about the role of religion within FGM. No participants expressed doubt in their religious beliefs, however the view that religion had been misappropriated to support the practice of FGM, also related to the emotional impact on women of FGM.

Women perceived FGM as being a necessary component of womanhood; as without it, they were considered not to have value in society. This conceptualisation related to the emotional impact of FGM as it enhanced many of the participant's anger towards the practice. This, together with the women's understanding of the gendered role of men, was central to the social norm of perpetuating FGM and its impact upon women's identity.

Women further understood the practice of FGM as being the result of pressure from the extended family. In many countries, due to the power of the extended family, birth parent consent was not required for FGM to be performed on a daughter. Analysis highlighted that this related to the conceptual code of fear, as women stated that they were scared to take their children back to their home countries for fear that a relative may carry out FGM on their daughters without their permission. As fear was impacted by women's conceptualisation, as well as then further compounding the impact of FGM, it was positioned within the conceptual framework between these two components to indicate its mediating power. This influenced the relational impact of FGM, with women reporting difficulties trusting others.

\section{Stage of life}

Analysis of the interviews revealed a strong inter-relation between the death of their own mother; menstruation; sexual relationship/marriage; childbirth and becoming a mother and the impact of FGM. The strong association analysis revealed between each of these facets led them to be categorised together within the conceptual framework as being significant stages in the women's lives. As the stage of life, as well as fear, appeared to reciprocally frame other elements of women's experience, it was positioned following analysis as being impacted by conceptualisations of FGM, yet as impacting other elements.

Women stated that the emotional impact of FGM was greatly influenced by the passing away of their mother, which filled survivors with a sense of obligation to forgive their mothers for allowing FGM to be performed on them. This led many survivors to feel conflicted. This impacted on their resilience, with survivors describing a reduced ability to resist the practice due to the death of their mother leaving them feeling powerless.

Women described menstruation as a reminder of FGM and some women of Muslim religion expressed how this affected their ability to manage the impact of FGM as women cannot pray whilst menstruating. Menstruation affected both the emotional and physical impact of FGM, with all the survivors stating that menstruation reminded them of FGM due to the physical health complications, which made it painful. 
Quotes illustrating the conceptual code 'Stage of life'

\begin{tabular}{|c|c|c|}
\hline $\begin{array}{l}\text { Conceptual } \\
\text { code }\end{array}$ & Axial code & Verbatim Quotations \\
\hline \multirow{4}{*}{ Stage of Life } & $\begin{array}{l}\text { Death of } \\
\text { own mother }\end{array}$ & $\begin{array}{l}\text { 'She didn't protect me and she was the one person that should have you know } \\
\text { protecting me and then she put me through this and how ignorant she was and } \\
\text { this is my anger fuming. 'mm' but then one of those occasions where you have to } \\
\text { get worse before you get better [mm] now to be honest (pause) I think because of } \\
\text { the fact that she has passed away as well makes me think maybe I forgiven her'. } \\
\text { (Faridah, Lines } 91-95 \text { ) } \\
\text { 'It's a forgiveness that comes with the fact that she has passed away... so I feel like } \\
\text { as if I've been left with no option other than to because if I carry on the anger any } \\
\text { more it's just going to damage me'. (Faridah, Lines 103-103) }\end{array}$ \\
\hline & Menstruation & $\begin{array}{l}\text { 'I'm practising Muslim, I try to practice Islam, and pray } 5 \text { times a day and fast and } \\
\text { you know things like that in the week that women have their periods they are } \\
\text { exempted from praying and fasting and all of those things, and because I'm not } \\
\text { praying and I don't have that sort of spiritual awakening or consciousness I sink } \\
\text { into a deep depression and then the smells and the connection with my femininity } \\
\text { and all of that brings back memories that put me in a really down place'. (Faridah, } \\
\text { Lines 175-181) }\end{array}$ \\
\hline & $\begin{array}{l}\text { Sexual } \\
\text { relationship } \\
\text { / marriage }\end{array}$ & $\begin{array}{l}\text { 'but I think it's a sexual abuse as well because something is done to that part of } \\
\text { your body so anything that you know getting your period, when I first got married } \\
\text { and have to have sex, you know penetration er [pause] just anything that happens } \\
\text { to women [mm] is just difficult and painful'. (Faridah, Lines 188-191) } \\
\text { '...like when you have sex the first time, when you have a child, first time having } \\
\text { marriage ... and all kind big life things you feel the pain and I wouldn't feel the pain } \\
\text { if I didn't have it'. (Zahara Lines 306-308) }\end{array}$ \\
\hline & $\begin{array}{l}\text { Childbirth } \\
\text { and } \\
\text { becoming a } \\
\text { mother }\end{array}$ & $\begin{array}{l}\text { 'My baby nearly died and all because of the FGM. They cut me and tore me to get } \\
\text { her out. It was the first time I felt really angry'. (Jamina, Lines 105-107) } \\
\text { 'As soon as I had my baby, I feel more to love my baby and I said no no no. This } \\
\text { one not going to be happening to you'. (Lines } 291 \text {, Saleema) }\end{array}$ \\
\hline \multirow[t]{2}{*}{ Fear } & Womanhood & $\begin{array}{l}\text { 'Because I heard the other girls, the ones who marry and they explained to us } \\
\text { what's going to happen so I was too scared to meet a man'. (Sabina, Line } 163 \text { ) } \\
\text { 'I was terrified of having my baby. I knew that women with circumcision have lot } \\
\text { of problem when having a baby as it doesn't come out and they have to be cut, so } \\
\text { I was very very scared. I thought they were going to butcher me again, like when I } \\
\text { first had you know, the cut'. (Ebony, Lines } 46-48 \text { ) } \\
\text { 'I am frightened each month to get my period knowing it was going to be painful' } \\
\text { (Sabina, Line 140) }\end{array}$ \\
\hline & $\begin{array}{l}\text { Ability to } \\
\text { cope }\end{array}$ & $\begin{array}{l}\text { When I think of FGM I feel frightened to be honest, but it's a good frightened as } \\
\text { it reminds me of what I went through and makes me strong'. (Asha, Lines 161- } \\
\text { 162) }\end{array}$ \\
\hline
\end{tabular}

Source: own research

\section{Fear}

While analysis revealed that fear influenced both the impact of FGM, as well as women's ability to enhance their resilience, hence its position as central to each of these components in the developed conceptual framework, women strongly related fear with womanhood and their ability to cope. It was 
therefore deduced that these two facets would form the axial codes within the category of fear. This is demonstrated in the quote denoted in Table 3.

Table 3

Quotes illustrating the conceptual code 'Fear'

\begin{tabular}{|l|l|l|}
\hline $\begin{array}{c}\text { Conceptual } \\
\text { coding }\end{array}$ & \multicolumn{1}{|c|}{$\begin{array}{c}\text { Axial } \\
\text { coding }\end{array}$} & \multicolumn{1}{c|}{ Verbatim Quotations } \\
\hline \multirow{3}{*}{ Fear } & Womanhood & $\begin{array}{l}\text { '...I live in fear that my husband will leave me and find a lady who wants } \\
\text { sex or who is not pained by it".(Wilo,Line 34) } \\
\text { 'I am frightened each month to get my period knowing it was going to be } \\
\text { painful' (Sabina, Line 140) }\end{array}$ \\
\cline { 2 - 3 } & $\begin{array}{l}\text { Ability to } \\
\text { cope }\end{array}$ & $\begin{array}{l}\text { When I think of FGM I feel frightened to be honest, but it's a good } \\
\text { frightened as it reminds me of what I went through and makes me strong'. } \\
\text { (Asha, Lines 161-162) }\end{array}$ \\
\hline
\end{tabular}

Source: own research

Women voiced fear relating to aspects of womanhood particularly their sexual relationships, which enhanced the relational, identity, and emotional impact of FGM. Women particularly emphasised a fear of rejection by men.

Further feelings of fear concerning womanhood related to stage of life, including menstruation, as well as childbirth. It is due to their strong inter-relationship that they are petitioned within the conceptual framework as factors which relate to each other both outside of the other impacts, as well as influencing other impacts. Their relationship was intensified if women had family or friends who had experienced complications with childbirth as a result of FGM. This related to the physical impact of FGM, with some women expressing how the feeling of fear led them to experience physical symptoms such as headaches and nausea.

\section{Impact on identity}

Feeling different; identity as a woman; loss of childhood identity and unknown identity were all unveiled during analysis and were catalogued together as being elements of identity. As represented by the interlinking circles within the conceptual framework, the impact of identity was viewed by women not as an isolated facet, but rather as being integral to the physical, emotional and relational impact of FGM. Verbatim quotations illustrating this conceptual code can be seen in Table 4.

Survivors of FGM felt they were different from women who had not had FGM, which was accentuated by living in the UK where FGM is not 'the norm'. The illegality of FGM in the UK also led women who expressed their belonging to a practising community to be judged harshly by society, leading them to feel stigmatised. This impact on identity related to women's perceptions of the healthcare system where they felt misunderstood and judged by professionals. This in turn exacerbated the negative emotional impact of FGM.

FGM impacted upon participant's identity as a woman, with survivors reporting that the procedure made them feel less feminine. This was strongly related to women's conceptualisation of FGM as being performed due to their gender, thus generating conflicted feelings towards their female identity. As shown in the framework (Figure 1), female identity was further threatened by the physical impact of FGM. Being 'cut' often caused women pain when engaging in sexual relationships and survivors reported their identity as a woman to be compromised. This impact was compounded by women's fear of having intimate relationships, as well as their understanding of the reasons for performing FGM as being to make them 
more marriageable and to enhance male sexual pleasure. Furthermore, the negative impact of FGM on female identity was exacerbated during different key stages of women's lives including menstruation and giving birth.

Table 4

Quotes illustrating the conceptual code 'Impact on Identity'

\begin{tabular}{|c|c|c|}
\hline $\begin{array}{c}\text { Conceptual } \\
\text { code }\end{array}$ & Axial code & Verbatim Quotations \\
\hline \multirow{4}{*}{$\begin{array}{l}\text { Impact of } \\
\text { Identity }\end{array}$} & $\begin{array}{l}\text { Feeling } \\
\text { different }\end{array}$ & $\begin{array}{l}\text { When I went to have the baby, they realise I have the FGM. I went to labour early } \\
\text { and was very scared. When I got to the hospital the nurse ... er the midwife... she } \\
\text { look at me and shouted for someone to come and look at me ... you know down } \\
\text { below... Because she had never seen the FGM before and the baby was already } \\
\text { trying to come out. The way she look at me ... it made me more scared and feel } \\
\text { like such a freak ... er like I was different to normal people'. (Jamina, Lines } 85-91 \text { ) }\end{array}$ \\
\hline & $\begin{array}{l}\text { Identity as a } \\
\text { woman }\end{array}$ & $\begin{array}{l}\text { 'I guess you could say I am not really a woman, I don't have all the parts that make } \\
\text { me a woman'. (Halina, Lines 126-127) } \\
\text { FGM took away my ability to be a woman by tearing, cutting and destroying me. I } \\
\text { will never get over the loss of my womanhood, silly really as I never really got to } \\
\text { know it. (Samina, Lines } 1598-1599 \text { ) }\end{array}$ \\
\hline & $\begin{array}{l}\text { Loss of } \\
\text { childhood } \\
\text { identity }\end{array}$ & $\begin{array}{l}\text { '...It took [my childhood] because the things I would do when I was young I wasn't } \\
\text { able to do it. When I see my kids, they play or whatever they want to do. I feel I } \\
\text { missed my childhood'. (Saleema, Lines 156-157) }\end{array}$ \\
\hline & $\begin{array}{l}\text { Unknown } \\
\text { Identity }\end{array}$ & $\begin{array}{l}\text { 'I know what happened changed me. I will never know if I was going to be the } \\
\text { person I am or the child I was... she's taken that away from me. I will never know } \\
\text { that, I will never know how it's like not to have someone ... inserting fingers inside } \\
\text { of you.' (Vada Lines } 407-410 \text { ) } \\
\text { 'Yes, o yes. I don't know how FGM changed me but it did, I just will never get to } \\
\text { find out how as I can never change it. It's gone, and so is how I was before it'. } \\
\text { (Asha, Line 158) }\end{array}$ \\
\hline
\end{tabular}

Source: own research

\section{Emotional impact}

The emotional impact of FGM was evident as influencing all other impacts of FGM, thus it was lobbied to be positioned within the conceptual framework as reciprocally being influenced by women's conceptualisations of FGM, as well as their stage of life and the fear they felt. As well as reciprocally influencing the physical, relational, and identity impact, as well as ability to exert resilience in women. The central codes identified included anger, remembering, shame and avoidance, quotations illustrating this code are included in table 5.

Many of the women described feelings of anger, which impacted on their lives in different ways. Some women expressed anger towards the perceived misrepresentation of religion as a reason to carry out FGM, whilst other women expressed anger towards their mother. This emotional impact was associated with the relational effect. These two core codes further relate to the anger women feel towards men, which impacted on their relationships. This is associated with women's understanding of FGM as being for the benefit of men. 
Quotes illustrating the conceptual code 'Emotional impact'

\begin{tabular}{|c|c|c|}
\hline $\begin{array}{l}\text { Conceptual } \\
\text { code }\end{array}$ & Axial code & Verbatim Quotations \\
\hline \multirow{4}{*}{$\begin{array}{l}\text { Emotional } \\
\text { impact }\end{array}$} & Anger & $\begin{array}{l}\text { 'I understand why people take a gun ... and shoot people, it's not an excuse but } \\
\text { sometimes I feel so angry with the impact of FGM'. (Vada, Line 464) } \\
\text { 'FGM makes me angry because of the culture, they believe you have to have it } \\
\text {... it makes me angry'. (Zahara, Line 251) } \\
\text { 'In my head I've killed her [mum] } 100 \text { times'. (Vada, Line 481) } \\
\text { 'I hate her for what she did, I can't have photo's about of her as it makes me } \\
\text { too angry'. (Saskia, Line } 47 \text { ). } \\
\text { 'It makes me so angry that because I am a woman that I don't get to enjoy the } \\
\text { life that everyone else gets. I don't get to enjoy sex and I don't get a good life all } \\
\text { because of being a lady. I feel so so angry and so upset and angry, I don't even } \\
\text { have the words for how angry I feel when I think about the FGM'. (Saskia, Lines } \\
66-68 \text { ) }\end{array}$ \\
\hline & $\begin{array}{l}\text { Remembering } \\
\text { FGM }\end{array}$ & $\begin{array}{l}\text { 'I think smell, there's certain smells that when I smell I think, o this smells } \\
\text { familiar and it reminds me of the circumcision and er it's I think it's after the } \\
\text { practice has been done and you know you have been cut out of sewing happens } \\
\text { and your legs are sort of tied together and when you first go to pee it's so painful } \\
\text { that moment and the smell I think there's certain smells [long pause] [that bring } \\
\text { that back] yeah bring that back'. (Faridah, Lines 169-173) } \\
\text { 'Difficult yeah. I remember always. Especially when I have problems like with } \\
\text { my health and doctors say it's because of FGM. You always remember it'. } \\
\text { (Ebony, Lines 119-120) } \\
\text { 'They decide to cut me, and when she went to do it she didn't explain to me and } \\
\text { I panic. I nearly kick her. Two of the nurses held me down. That was it...I was } \\
\text { a little girl again being held down. Suddenly I could smell the blood and the } \\
\text { room where I had the cut in the first place. I would see the lady who done it to } \\
\text { me, only she didn't look kind she looked mad at me. Like she wanted to hurt } \\
\text { me. It was like a bad dream and I couldn't wake up'. (Jamina, Lines 93-98) } \\
\text { 'Most nights I hear her [sister] in my dreams screaming having her FGM'. } \\
\text { (Fabia, Line } 77 \text { ) } \\
\text { '...Every time someone grab me from behind, I jump and for a split second I } \\
\text { think it the cutters again. Sometimes I turn the corner and I see them even } \\
\text { though there is no one there'. (P16, Saskia, Line 88) }\end{array}$ \\
\hline & Shame & $\begin{array}{l}\text { 'No I didn't talk to anyone because I felt ashamed that I could not have the sex } \\
\text { as other people would think I didn't love my husband'. (Jamina, Lines 70-71) } \\
\text { 'Sometimes it feel like embarrassing that people talking about your private parts } \\
\text { in public place, often when people talk about FGM I feel like they are looking } \\
\text { at me and I just want the ground to open. I feel so ashamed it has happened to } \\
\text { me.' (Fabia, Line 303-304) }\end{array}$ \\
\hline & Avoidance & $\begin{array}{l}\text { 'Sometimes I remember in the day but always I try to forget, I don't want to } \\
\text { remember'. (Ebony, Line 217) } \\
\text { '...I was so scared of childbirth I kept fainting and the doctor she got cross with } \\
\text { me in the end and said I was doing it on purpose, but that wasn't true. I don't } \\
\text { even remember the birth [were you given pain relief?] no I was given nothing } \\
\text { but I had to pretend it wasn't me there as the pain was far far too bad as they } \\
\text { had to cut me up again'. (Neema, Lines 52-56) } \\
\text { '...I dream that the lady who cut me and when I wake up I can physically still } \\
\text { feel the pain. Technically there is no pain, but when I wake up from the dream, } \\
\text { all I feel is the physical pain and yet I don't feel sad'. (Keisha, Lines 105-106) }\end{array}$ \\
\hline
\end{tabular}

Source: own research 
The women interviewed highlighted different situations, sounds, and smells that elicited vivid recollections of FGM. These strongly related to the relational and physical impact of FGM, with some women stating that sexual intercourse reminded them of the procedure leading to the experience of flashbacks. Remembering FGM was heightened by the core concepts of fear, unmet needs, and stage of life. Women expressed being fearful of encountering situations which elicited flashbacks including sexual intimacy. Women were also particularly fearful of giving birth, which related to the physical and emotional impact and also linked to the lack of service understanding, leading to women feeling that their psychological needs were neglected. Women identified strong feelings of shame due to being an FGM survivor, which was exacerbated at different stages of their life, particularly during childbirth. Shame was further enhanced by women's perception that their needs were not adequately met by services and the reaction of health professionals to their FGM.

For some women, the emotions associated with FGM were experienced as intolerable and they described dissociating (cutting off emotionally as a response to a traumatic experience) to manage this. This was associated with both the physical and relational impact of FGM, with women describing intercourse as being a trigger to dissociation. Other women described somatisation (expressing physical problems for emotional distress), where the emotional and physical impact of FGM strongly inter-related, as emotional pain was expressed as physical pain. The effect of this was intensified by a perceived lack of a holistic approach by services of the care and treatment of FGM survivors.

\section{Relational impact}

Positioned both in line with, and interlinked with the emotional, identity and physical impact, analysis showed FGM had a negative impact on women's relationships. As depicted in Table 6, four axial codes were revealed including attachment with child; marital relationship; relationship with mother and trust.

Table 6

Quotes illustrating the conceptual code 'Relational Impact'

\begin{tabular}{|c|c|c|}
\hline $\begin{array}{l}\text { Conceptual } \\
\text { code }\end{array}$ & Axial code & Verbatim Quotations \\
\hline \multirow{3}{*}{$\begin{array}{l}\text { Relational } \\
\text { impact }\end{array}$} & $\begin{array}{l}\text { Attachment } \\
\text { with child }\end{array}$ & $\begin{array}{l}\text { 'I blame FGM! If it wasn't for that I would have had a normal childbirth and my } \\
\text { daughter would love me, but they had to cut me and I think I resented my } \\
\text { daughter for the pain I went through for a while'. (Neema, Lines 62-63) } \\
\text { I couldn't really walk or move for a few weeks after they cut me, so it took long } \\
\text { time for me to care about the baby. My sister looked after the baby until I could } \\
\text { walk and the baby never really remembered I was her mother. (Neema, Lines 58- } \\
60 \text { ) }\end{array}$ \\
\hline & Trust & $\begin{array}{l}\text { 'I have people I live with [mm] but friends? um ... um ... mmm... [laughs] that } \\
\text { sounds so bad that I've never had friends ... this friend issue...I don't have ... I } \\
\text { have trust issues'. (Vada, Lines, } 100-101 \text { ) } \\
\text { 'I want to trust people yes, but I am scared to trust. I want to trust people yes, } \\
\text { but I am scared to trust'. (Keisha, Lines } 57-58 \text { ) }\end{array}$ \\
\hline & $\begin{array}{l}\text { Impact on } \\
\text { marital } \\
\text { relationship }\end{array}$ & $\begin{array}{l}\text { 'He might look around to have another to marry and to have another wife maybe, } \\
\text { because you're not ... you know you showing yeah you don't care [mm] and it } \\
\text { seems to him 'she doesn't like me, she doesn't like me'... so you have to pretend.' } \\
\text { (Saleema, 266-167). } \\
\text { 'I was too shy to ask him. The marriage was normal but to ask those kind of } \\
\text { things I was too shy if I feel pain or if I feel no pain, I was shy to tell him. FGM } \\
\text { create like a wall between us as even now I am scared to speak with him about } \\
\text { it'. (Zahara Lines 166-167) }\end{array}$ \\
\hline
\end{tabular}




\begin{tabular}{|l|l|l|}
\hline & $\begin{array}{l}\text { 'I try to avoid definitely. Normal women they relax and enjoy sex but for the } \\
\text { woman with FGM, no I don't enjoy sex. I try and avoid that part of my } \\
\text { relationship, what's the point when I get no pleasure?' (Alia, Lines 202-203) }\end{array}$ \\
\cline { 2 - 3 } & $\begin{array}{l}\text { 'She had to leave the room because it was too painful for her to watch me go } \\
\text { through the practice that made me really angry really angry that she went out of } \\
\text { the room save herself but didn't think of me'. (Faridah, Lines 81-83) } \\
\text { 'Fith mother }\end{array}$ \\
$\begin{array}{l}\text { 'FGM broke me and my mother's relationship for good, if you love your child } \\
\text { you cannot hurt them, she was happy to hurt me' (Filomena, Lines 56-58) } \\
\text { '...why did my mother not protect me from this, in fact on the contrary she's the } \\
\text { one who put me through this' (Faridah, Line 220-221) }\end{array}$ \\
\hline
\end{tabular}

Source: own research

Women related how due to the chronic and longstanding physical pain arising from complications with childbirth, they were often unable to care for their child as they would have liked. For some survivors they felt this compromised the bond and subsequent attachment between mother and child. It is for this reason that the impact on relationships was positioned in the model as overlapping with the physical impact of FGM. Other women described feeling resentful towards their child due to the physical pain they experienced as a result of FGM during childbirth. The relational impact in many women enhanced their determination to advocate against the practice, with a sense of duty that they needed to protect their child. Resilience was further intensified by the over-riding fear women experienced that their daughter may be put through FGM if they did not protect them.

Women interviewed revealed that having FGM impacted on their ability to trust others, particularly other women. This further increased the fear they felt and prevented some women from making friends and reducing opportunities for support and action, hence its position within the conceptual framework as being related to fear and ability to enhance resilience.

\section{Physical impact}

This category encapsulated three axial codes including: pain; pregnancy and childbirth and health complications. These physical effects were compounded by women's perception that their holistic (physical and mental health) needs associated with the impact of FGM were not fully addressed by service providers. This was felt to justify the position of service provision at the bottom of conceptual framework, as it served to worsen the impact and ability of women to implement resilience.

Many women interviewed reported experiencing long term pain and other physical health complications due to FGM. Women described these health problems as being more intense during particular stages of their lives including menstruation. This related to the fear women felt, with them describing feeling frightened prior to menstruation. Survivors believed this reduced their resilience and increased the negative emotional impact of FGM. This was associated with the relational impact of FGM, with women expressing social isolation at times of increased physical pain.

The relationship between the physical and emotional impact of FGM was further demonstrated by women reporting difficulties delivering children, often having to be 're-cut' (de-infibulation) to facilitate delivery. Five women interviewed had tragically lost children during childbirth due to the physical health complications of FGM. The impact of which was intensified due to a perceived lack of understanding of their specific needs by health professionals. The physical effects of losing a child strongly enhanced women's determination to resist the continuation of the practice of FGM on their daughters. 
Quotes illustrating the conceptual code 'Physical impact of FGM'

\begin{tabular}{|c|c|c|}
\hline $\begin{array}{l}\text { Conceptual } \\
\text { code }\end{array}$ & Axial code & Verbatim Quotations \\
\hline \multirow{3}{*}{$\begin{array}{l}\text { Physical } \\
\text { impact }\end{array}$} & Pain & $\begin{array}{l}\text { 'Yes, you know the pain of FGM it never go. For the rest of your life you have pain like } \\
\text { me'. (Sabina, Line 144) } \\
\text { '...Personally, the physical consequences I had is having sex ... it's always hard because } \\
\text { when you are closed ... after having sex you feel some pain and bruised'. (Samina, Line } \\
470) \text {. }\end{array}$ \\
\hline & $\begin{array}{l}\text { Pregnancy / } \\
\text { Childbirth }\end{array}$ & $\begin{array}{l}\text { 'I lost my baby completely at four months old [mm] ... It was } 20 \text { weeks pregnant and I } \\
\text { had bleeding, starting bleeding and the baby comes out and then I had er ... [at } 20 \text { weeks?] } \\
\text { at } 20 \text { weeks, because of the pressure of looking at the husband he wants to use it, you're } \\
\text { closed ... you're going to give birth... how do they open for you? All those kind of things } \\
\text { I was worried about'. (Saleema, Lines } 218-222 \text { ) } \\
\text { 'The problem come with that one because after I give birth they stitch it too much and } \\
\text { when I come back home I had swollen my legs [o your legs were swollen?], yea legs were } \\
\text { swollen ... too much swollen, and I had infection ... um ... temperature, I can't walk, I } \\
\text { can't even feed my baby [yeah] and after one year I had operation to open again [ok] yeah } \\
\text { because difficult to do the urine and when I had um periods it was difficult [mm] ... } \\
\text { feelings too much pain'. (Ebony, Lines } 64-68 \text { ) } \\
\text { 'I went into the labour and they did not realise I was stitched and when they realised it was } \\
\text { too late and...and [pause]...they called the doctor but by the time he got there she was } \\
\text { blue. She had died; they couldn't get her out in time. She was perfect and FGM took her } \\
\text { away from me. (Filomena, Lines 37-39) }\end{array}$ \\
\hline & $\begin{array}{l}\text { Health } \\
\text { complication }\end{array}$ & $\begin{array}{l}\text { 'As soon as I start my period I feel pain [mm]. Even before I used to have infection all the } \\
\text { time ... Yeah urine infections all the time. And then as soon as I started having periods } \\
\text { still continues'. (Saleema, Lines 130-132) } \\
\text { 'The problems I have until now because even now I have problem with the urine ... yeah } \\
\text { I can't do the urine when I'm on toilet ... I'm pushing but it's not coming out, all the urea } \\
\text { stays in my bladder and give me infection'. (Ebony, Lines 96-97) }\end{array}$ \\
\hline
\end{tabular}

Source: own research

\section{Psychological resilience}

Women had different interpretations of what it meant to cope with the impact of FGM, however when considered in tandem to one another, analysis revealed strong associations between conceptualisation of survivor's experience as 'lucky'; a sense of duty; empowerment; and resistance, understanding these to be reflective of psychological resilience. As resilience was argued by women to be impacted by service provision, as well as women's stage of life, and relational, physical, identity and emotional impact, it was positioned within the conceptual framework as an entity which stood alone yet was globally impacted.

Despite describing numerous effects of FGM on their lives, all the women interviewed considered themselves 'lucky' that their impact of FGM was not as bad as others. This, together with their sense of duty to campaign against FGM, enhanced women's resilience and ability to cope with the physical and emotional impact of this procedure. Women's psychological resilience was influenced by their stage of life including menstruation, childbirth and sexual intimacy, which both enhanced women's ability to be resilient, and at other times inhibited it. All the women expressed that they would not let their daughters have FGM as they did not want their daughters to have experiences similar to their own. 
Quotes illustrating the conceptual code 'Resilience'

\begin{tabular}{|c|c|c|}
\hline $\begin{array}{l}\text { Conceptual } \\
\text { code }\end{array}$ & Axial code & Verbatim Quotations \\
\hline \multirow{4}{*}{$\begin{array}{l}\text { Psychological } \\
\text { Resilience }\end{array}$} & $\begin{array}{l}\text { Duty to share } \\
\text { knowledge }\end{array}$ & $\begin{array}{l}\text { 'And it's my responsibility to tell my daughters how bad FGM is and tell them everything } \\
\text { I know about how bad it is'. (Halina, Lines } 164-165 \text { ) } \\
\text { '...I fight with everything I have against FGM ... I am not a campaigner or nothing, but } \\
\text { if anyone says about FGM I warn them against it'. (Larissa, Lines 468-469). }\end{array}$ \\
\hline & Luck & $\begin{array}{l}\text { 'When I hear stories of you know because I am always active in the FGM campaign and } \\
\text { attend a lot of talks and hear a lot of survivors stories and sometimes when I hear the } \\
\text { amount of physical pain they have gone through ... thank God you know the least of my } \\
\text { pain is the physical pain'. (Faridah, Lines } 267-269 \text { ) } \\
\text { 'To be honest with you I am lucky because some people have the hard one and its very } \\
\text { very extreme whereas mine ... at least I am alive, some girls they die. Compared to some } \\
\text { ladies I am lucky only being in a little bit of pain every day, not a lot'. (Fabia, Line 216- } \\
218 \text { ) } \\
\text { 'I was lucky; I didn't have many health problems, and my baby was ok as I had the } \\
\text { stomach cut [C-section] ... the only pain I have is period pain every month as it gives me } \\
\text { lots of the urination infections' (Keshia, Lines 34-36) }\end{array}$ \\
\hline & Empowerment & $\begin{array}{l}\text { 'I think the fact that I'm helping other women you know I think... I remember making } \\
\text { a conscious decision that I need to do something about FGM and help other women } \\
{[\mathrm{mm}] \text { and you know we say in Islam if you save the life of one person it's like as if you }} \\
\text { have saved humanity. And in my mind I think what keeps me going is as an FGM } \\
\text { campaigner, speaker out there and all that and thinking you know what I'm going to } \\
\text { speak out about it and do something about it and if I can help one girl not to go through } \\
\text { FGM [mm] then my life is worth it'. (Faridah, Lines 414-418) } \\
\text { 'I'm the one in my family the new family I created to break that circle [mm] so for me it } \\
\text { just ... rather than feel sorry for myself and seen as a victim I see myself as a winner in } \\
\text { this battle, FGM battle'. (Larissa, Lines } 457-458 \text { ) }\end{array}$ \\
\hline & $\begin{array}{l}\text { Resisting } \\
\text { continuation of } \\
\text { FGM }\end{array}$ & $\begin{array}{l}\text { '...people they ask you why the girls they don't have it, and I say and answer that I don't } \\
\text { want them to feel like I feel because my feeling was not good [mm] and my relationship } \\
\text { not good because of FGM so I don't want to do my girls the same [mm]. They have to } \\
\text { feel more attractive and sexy you know ... my girls to feel comfortable'. (Amina, Lines } \\
30-33 \text { ) } \\
\text { 'I have an } 18 \text { year old and I never touch her... I wouldn't do it because it's ...there is } \\
\text { no explanation anywhere saying you have to do it and I don't want anyone to go through } \\
\text { what I did'. (Fabia, Lines 107-109) }\end{array}$ \\
\hline
\end{tabular}

Source: own research

\section{Limited service provision}

Lack of professional knowledge; need for a special service; need for validation; and talking therapy were also considered within the analysis to be reflective of a lack of service provision to support women, and hence compounded all other understandings and impacts of FGM. Verbatim quote for this code are evidenced in Table 9.

Women stated that their dissatisfaction with service providers stemmed from a lack of professional knowledge regarding FGM and their wish for holistic service responses including physical and mental health approaches. This perceived lack of knowledge by professionals led FGM survivors to feel stigmatised thereby increasing the emotional impact on them. A lack of understanding by professionals also affected women's responses to services as stigmatisation led survivors to avoid attending for cervical cancer screening for instance.

Lack of appropriate and sensitive health service provision also increased the physical and emotional impact of FGM, and participants considered that there was significant need for more specialist services. 
Due to their difficulties with sexual intercourse, menstruation, and giving birth women felt there was a need for clinics that could 'reverse' the physical effects of FGM. A particular need was reported by survivors interviewed for greater support following childbirth, due to the combination of the physical complications of FGM as well as the associated psychological stress.

The emotional impact was further enhanced by the lack of emotional support available through the NHS. Women expressed that increased psychological support was needed within health services, whilst some participants preferred the idea of having individual therapy, others felt they would feel safer with group therapy. The need for increased psychological services was considered by women to be particularly required within maternity services due to the impact of their experiences on the maternal bond, attachment with their child and the impact of infant mortality.

Table 9

Quotes illustrating the conceptual code 'Limited service provision'

\begin{tabular}{|c|c|c|}
\hline $\begin{array}{l}\text { Conceptual } \\
\text { code }\end{array}$ & Axial code & Verbatim Quotations \\
\hline \multirow{4}{*}{$\begin{array}{l}\text { Limited } \\
\text { service } \\
\text { provision }\end{array}$} & $\begin{array}{l}\text { Lack of } \\
\text { professional } \\
\text { knowledge }\end{array}$ & $\begin{array}{l}\text { 'People see when they look at us as a victim because they don't have knowledge } \\
\text { of FGM, and that's what are women are scared to look for a service that people } \\
\text { see them as a victim [ok] or someone suffering. (Larissa Lines 560-563) } \\
\text { 'No, would never use health services here. Doctors in the UK don't understand } \\
\text { FGM, they cause more problems by not understanding'. (Asha, Lines 166-167) } \\
\text { Woman professionals say 'those people [FGM survivors] don't deserve to have } \\
\text { children, they are barbaric'. Ignorance and this is the worst that we hear from } \\
\text { professionals...they ignorant. Larissa (Lines } 607-610 \text { ) }\end{array}$ \\
\hline & $\begin{array}{l}\text { Need for } \\
\text { specialist } \\
\text { services }\end{array}$ & $\begin{array}{l}\text { 'They need to have someone that talks to you before and while you have a baby. } \\
\text { I would have wanted someone to help me and tell me what was going to happen } \\
\text { but I never got that. That would be helpful. You know someone who was specially } \\
\text { trained so you only see people who understand FGM.' (Patience, Lines } 86-89 \text { ) } \\
\text { 'I think it's good to be able to talk and make a clinic where we can have a group } \\
\text { to talk about they feel and also somewhere they if we have been cut we can be } \\
\text { opened before we get married.' (Alia, Lines } 225-226 \text { ) } \\
\text { '...I think that they should have pregnancy support so that women who may have } \\
\text { infection like me do not miss out on their child growing up, so they can continue } \\
\text { to be a mum'. (Wilo, Lines } 62-63 \text { ) }\end{array}$ \\
\hline & $\begin{array}{l}\text { Need for } \\
\text { validation }\end{array}$ & $\begin{array}{l}\text { 'It was just the way she dealt with the whole thing, she was deeply deeply caring } \\
\text { and she was really deeply moved. She was just a doctor to examine me and then } \\
\text { er I think it was just have sensitively with the whole thing [yeah] just stuck in my } \\
\text { memory'. (Faridah, Lines 359-341) } \\
\text { 'It was one of those moments where you think Ok I'm not going crazy I'm not } \\
\text { the one who's thinking something horrible happened to me[ yeah] look at this } \\
\text { stranger you know, so it was just really good feeling I remember feeling really } \\
\text { warm really feeling you know'. (Faridah, Lines 367-368) }\end{array}$ \\
\hline & $\begin{array}{l}\text { Talking } \\
\text { therapy }\end{array}$ & $\begin{array}{l}\text { 'Even now I think about my baby birth and get scared and if I had had someone } \\
\text { to talk about it with they maybe would be easier. My friend she had a councillor } \\
\text { and she say it was very helpful. The lady she helped her understand and } \\
\text { comprehend. I think all lady to have the FGM after and before the baby should } \\
\text { have councillor or some person like that'. (Amina, } 139 \text { - 143) } \\
\text { '...They need to have someone that talks to you before and while you have a baby. } \\
\text { I would have wanted someone to help me and tell me what was going to happen } \\
\text { but I never got that'. (Patience, Lines } 86-87 \text { ) } \\
\text { 'It's better to have a group because some women don't talk about it so it's better } \\
\text { to have an organised group to talk about FGM so they would see more women } \\
\text { talk and they would feel more happy to talk about how they feel'. (Zahara, Lines } \\
\text { 335-337). }\end{array}$ \\
\hline
\end{tabular}

Source: own research 


\section{DISCUSSION}

This research used in-depth interviews to explore women's experiences and the impact of FGM on their lives. A holistic conceptual framework was developed (Figure 1), which revealed that FGM survivors felt various reasons were used for the practice of FGM including: culture; religion; the role of men; lack of education; female identity; and deception. The social and cultural context was perceived to be extremely important by all the women interviewed and influenced the emotional, relational, identity, and physical impact of their experiences, and therefore their ability to enhance their psychological resilience. All of these factors were influenced by fear particularly at key stages of womanhood. Women's view of a lack of an effective, holistic and sensitive service response increased the negative impact of their experiences.

The conceptual framework outlined the complex and multifaceted factors relating to the psychological impact of FGM. Women viewed FGM as inherent to their identity as a woman and expressed that without FGM they would not be viewed by society as 'marriageable' as they would be considered 'impure' by their community, a finding supported by previous research (Ashimi \& Amole, 2015). However, this paper argues that FGM impacts significantly on women's identity and their relationship with other women in their family who they blamed for its continued practice and were angry with. This is particularly problematic within a patriarchal social structure where women find it difficult to access support from female friends and relatives.

Due to the physical impact of FGM, many women felt unable to sexually satisfy their male partner and therefore avoided sexual intimacy. Whilst physical health impact is acknowledged in the literature (Elnashar \& Abdelhady, 2007; Lundberg \& Gerezgiher, 2006), the conceptual framework reveals that participants related their ability to please their sexual partners as integral to their identity as a woman. Being unable to do so posed a challenge to their identity, which led to emotional conflict. This is consistent with research by Courtois (1979) into gender-based violence. In addition, the research for this article illustrates the severe gynecological and psychological impact of women's experiences of FGM needs to be viewed by professionals as a human rights issue that affects survivors' physical and psychological health. The authors therefore advocate a holistic approach which is sensitive to the range of survivors complex needs in their cultural context.

Due to the impact of the physical effects of FGM on identity, relationships, and ability to enhance resilience, the research argues for the development of specialist services where the physical effects of FGM can be reversed, including reconstructive surgery (which is currently not available on the NHS). Specialist services should include a clear assessment and specialist pathways whereby women's complex holistic needs, including psychological, social, cultural, human rights and physical health, could be thoroughly assessed and treated.

Women we spoke to felt they had been deceived by the wider community regarding the reasons for the continuation of the practice of FGM. In addition, the influence of the extended family in supporting and subjecting girls to FGM meant that many survivors we spoke to who tried to resist the practice, felt disempowered. The practice of FGM as a form of sexual control as well as the "blaming of women for its practice' led to the reinforcing of patriarchal values. As a result, participants felt distrustful of other women, thereby reducing their ability to unite and challenge patriarchal structures and practices. Professionals working with survivors need to be mindful of how patriarchal structures impact upon women's ability to trust others and therefore access support from other women and engage with support services.

The holistic conceptual framework presented in this paper facilitates a better understanding of how the interaction between the physical and relational impact of FGM related to the destruction and reconstruction of women's multiple identities; including being a woman, mother, and sexual partner. Women's construction of what it means to be a woman is intrinsically linked to notions of womanhood in Africa where a woman's worth is connected to her ability to have children (Bourke, 2013). Due to the physical 
health impact of FGM, some women had lost their babies due to complications giving birth. Losing a child in African culture is viewed as a 'double blow', due to the stigmatisation and rejection women experience from their communities (Layne, 2003). It is argued that maternity services need to be improved to have a greater cultural understanding of the meaning of losing a child for women from African communities and the resulting impact on their identity. In line with the holistic approach recommended services could also provide social and legal support for FGM survivors. Consistent with research by Liebling et al., (2012), this research accentuated the need to address the reproductive needs and rights of women and girls who experience FGM. Services could benefit from outcome measures, including qualitative information, to evaluate and monitor the effectiveness of their engagement with FGM survivors, including during pregnancy and childbirth.

The holistic conceptual framework describes the significant impact on the attachment relationship between mothers who had FGM and their child. By developing a greater understanding of the relationship between identity, physical health, and the relational impact of FGM, the research suggests that due to the physical health complications of giving birth, many women experienced separation from their child, or the inability to adequately attend to their child's needs. Women interviewed considered this to impact negatively on the bond with their child. Whilst no research has addressed this specific issue, it is generally well documented that traumatic childbirth and physical health complications can lead to difficulties in forming a secure mother-child attachment (Allen, 1998; Bailham \& Joseph, 2003).

The authors argue that the needs of FGM survivors are neglected after childbirth. This echoed research by Liebling et al., (2012) who found support after childbirth for rape survivors who became pregnant in Congo was limited to the detriment of their' post-natal health, as well as the welfare of their children. The current study argues for the pressing need to improve post-natal psychological and physical healthcare of FGM survivors to enable them to enhance their psychological resilience.

Furthermore, the conceptual framework highlights the need for a greater understanding within healthcare professionals of somatisation as a way of expressing the emotional distress survivors' experience. Failure of service providers to recognize this cultural expression of distress may stigmatise survivors and affect their ability to access appropriate services. It also exacerbates the emotional, identity, physical, and relational impact of FGM as well as having a negative impact on their psychological resilience.

Survivors perceived UK professionals to have limited knowledge and skills related to FGM, as well as stigmatising attitudes and body language. In conjunction with the shame expressed by women interviewed, these factors act as significant barriers for women accessing appropriate and sensitive support services and is consistent with existing research on sexual and gender-based violence (Hentonnen et al., 2008). It is argued that there is a need for international training and policy development amongst UK professionals to enhance holistic support for FGM survivors, which will increase their psychological resilience.

Novel findings emerged from this research regarding factors that enhanced women's psychological resilience. Data analysis revealed luck, sense of duty, empowerment, and resistance as important factors in enhancing resilience and these have also been emphasised in wider research into gender-based violence (Mahoney, 1994; Boyden, 2000; Liebling-Kalifani, 2009). This paper argues that resilience is influenced by fear, different stages of women's lives, limited service provision and lack of a culturally sensitive holistic approach. To enhance resilience, the authors recommend that there is need for increased and flexible social and psychological support for FGM survivors, in the form of individual and group therapy. The value of groups for survivors of sexual and gender-based violence is highlighted in previous research (Wright et al. 2003) where it is argued they can contribute to the development of collective empowerment and positive growth. 
An interesting finding of the research related to the religion and type of FGM which women were subject to. Whilst it may be assumed that this would influence the impact and understanding of FGM, analysis of the research revealed no differences in the type of FGM, or women's religion and the subsequent psychological impact of FGM. Whilst arguably further research would be beneficial to further explore this assertion, and indeed to test the utility of the model with a wider sample from differing religions and with women who have experienced different types of FGM, based on current findings there appears to be no tangible difference.

Whilst the findings are likely to be applicable to other countries; the current study focussed on women from the African Continent and therefore the results cannot be generalised. Future research could seek to develop and refine the holistic conceptual framework for women from different FGM practising communities. Furthermore, it is noted that the research held potential for study bias as whilst all women stated that they were very against the practise of FGM and argued that they would not / had not had FGM performed on their children, it is recognised that admission of a intention to have their daughters 'cut' would result in safe guarding involvement.

Due to the highlighted impact of childbirth and attachment, a more in-depth understanding of the impact of FGM on attachment between a mother and her child is needed in order to better inform services to improve support for affected women.

\section{CONCLUSION}

This study, based on qualitative research using grounded theory with FGM survivors, developed an evidence- based holistic conceptual framework for professionals dealing with the psychological and social impact of FGM and responses required for survivors and their children. It revealed the importance of services, which bring together in a holistic way the physical, human rights, social and psychological aspects of the impact of FGM, within the survivors' socio-cultural context. The research demonstrated the complex systems and relationships that influence the psychological and social impact of FGM including survivors' fears and provides key clinical and policy recommendations particularly in relation to maternity and healthcare services. Based on the results of this research, it is recommended that the holistic needs of survivors are addressed by service providers in a way that enhances their psychological resilience, bearing in mind the additional influence of the different stages of a woman's life. The study's recommendations include improvements in the healthcare system, particularly in relation to childbirth, as well as enhancing infantmother bonding and addressing menstruation and sexual health and relationship issues. There is need for additional psychological and social support for women experiencing traumatic effects including those survivors who are mothers and who have attachment difficulties and women experiencing flashbacks during sexual intercourse. Women's psychological needs could be addressed by the provision of a choice of individual or group therapy. The research also suggests increasing staff training on the reasons for and impact of FGM on survivors and their families including the socio-cultural context. Training would further enable service providers to appreciate the complex links between the physical, social and psychological impact on FGM survivors and assist in the development of specific health pathways for referrals.

\section{REFERENCES}

Allen, S. (1998). A qualitative analysis of the process, mediating variables and impact of traumatic childbirth. Journal of Reproductive and Infant Psychology, 16, 107-131.

Ashimi, A. O., \& Amole, T. G. (2015). Perception and attitude of pregnant women in a rural community north-west Nigeria to female genital mutilation. Archives of Gynaecology and Obstetrics, 291, 695-700. 
Bailham, D., \& Joseph, S. (2003). Post-traumatic stress following childbirth: a review of the emerging literature and directions for research and practise. Psychology, Health and Medicine, 8(2), 159- 168.

Barrett, H. Brown, K. Alhassan, Y. \& Beecham, D. (2015). The REPLACE Approach: Supporting communities to end FGM in the EU. A Toolkit. Coventry University, Coventry. www.replacefgm2.eu.

Bebbington, P., Jonas, S., Kuipers, E., King, M., Cooper, C., Brugha, T., Meltzer, H., McManus, S., \& Jenkins, R. (2011). Childhood sexual abuse and psychosis: data from a cross-sectional national psychiatric survey in England. British Journal of Psychiatry; 199, 29-37.

Berg, R. C., Denison, E. M., \& Fretheim, A. (2010). Psychological, social and sexual consequences of female genital mutilation/cutting (FGM/C): a systematic review of quantitative studies. Rapport fra Kunnskapssenteret. Norwegian Knowledge Centre for the Health Services.

Berg, R., Underland, V., Odgaard-Jensen, J., Fretheim, A. \& Vist, G. (2014). Effects of female genital cutting on physical health outcomes: a systematic review and meta-analysis. British Medical Journal Open, 4(11).

Bourke, D. (2013). Responding to HIV / AIDS. Tough questions, direct answers. Intervarsity Press.

Boyden, J., \& Gibbs, S. (1997). Children of War: Responses to Psycho-Social Distress in Cambodia. Geneva: The United Nations Research Institute for Social Development.

Brown, K., Beecham, D., \& Barrett, H. (2013). The applicability of behaviour change in intervention programmes targeted at ending female genital mutilation in the EU: integrating social cognitive and community level approaches. Obstetrics and gynecology international, 2013.

Bryant, A., \& Charmaz, K. (2007). The SAGE handbook of grounded theory. Los Angeles: SAGE.

Burstow, B. (2005). A critique of post-traumatic steess disorder and the DSM. Journal of Humanistic Psychology, 45(4). $429-445$.

Courtois, C. (1979). The Incest Experience and its Aftermath. Victimology 4, 337-347.

Girls Summit. (2014). Improving the lives of girls and women in the world's poorest countries. Department of International Development: Retrieved 20 ${ }^{\text {th }}$ March 2016 from: https://www.gov.uk/government/news/girl-summit-2014outcomes-and-commitments

Global Summit to End Sexual Violence in Conflict. (2014). Retrieved 20 $0^{\text {th }}$ March 2016 from https://www.gov.uk/government/topical-events/sexual-violence-in-conflict

Layne, L. (2003). Unhappy endings: a feminist reappraisal of the women's health movement from the vantage of pregnancy loss. Social Science Medicine, 56, 1881-1891.

LeVine, P. (1999). Assessing detachment patterns and contextual trauma across cultures (trauma detachment grid). The Refugee Studies Programme Seminar, June 3, University of Oxford.

Liebling, H., Slegh, H., \& Ruratotoye B. (2012). Women and girls bearing children through rape in Goma, Eastern Congo: Stigma, health and justice responses. Itupale Online Journal of African Studies, 4, 18-44.

Liebling-Kalifani, H. (2009). A gendered analysis of the experiences of Ugandan women war survivors. VDM Verlag Dr. Muller.

Liebling-Kalifani, H.J. (2010). Research and intervention with women war survivors in Uganda: Resilience and suffering as the consequences of war. In H. Bradby, and G. Lewando-Hundt, (Eds.). Global Perspectives on War, Gender and Health:Sociology and Anthropology of Suffering: Ashgate Books, 69-90.

Lockhat, H. (2004). Women's psychological experiences. In: H. Lockhat (Ed.). Female Genital Mutilation: Treating the Tears. 1st ed. England: Middlesex University Press. 118.

Lundberg, P., \& Gerezgiher, A. (2008). Experiences from pregnancy and childbirth related to female genital mutilation among Eritrean immigrant women in Sweden. Midwifery, 24(2), 214-225.

Macfarlane, A, \& Dorkenoo, E. (2015). Prevalence of female genital mutilation in England and Wales: National and local estimates. London: City University London and Equality Now.

Mahoney, M. (1994). Victimization or oppression? Women's lives, violence and agency. In M. Fineman and R. Mykitiuk (Eds.). The Public Nature of Private, 59-92.

Mulongo, P., Martin, C. H., and McAndrew, S. (2014). The psychological impact of female genital mutilation/cutting (FGM/C) on girls'/women's mental health: a narrative literature review, Journal of Reproductive and Infant Psychology, 32(5).

Read, J., Agar, K., Argyle, N., \& Aderhold, V. (2003). Sexual and physical abuse during childhood and adulthood as predictors of hallucinations, delusions, and thought disorder. Psychological Psychotherapy; 76, 1-22. 
The Female Genital Mutilation Act. (2003). Retrieved 1st April 2016 from: http://www.legislation.gov.uk/ukpga/2003/31/contents

UNICEF. (2016). $\quad$ Retrieved 23 $3^{\text {rd }} \quad$ March 2016 from: http://www.unicef.org/media/files/FGMC 2016 brochure final UNICEF SPREAD(2).pdf

United Nations Development Programme. (2015). Combatting female genital mutilation in Egypt. Retrieved 10 ${ }^{\text {th }}$ April 2016 from http://www.undp.org/content/dam/undp/fgminegypt/index.html

Wessells, M. G. (1999). Culture, power, and community: Intercultural approaches to psychosocial assistance and healing. In K. Nader, N. Dubrow \& B. Stamm (Eds.), Honoring Differences: Cultural issues in the treatment of trauma and loss. New York: Taylor \& Francis. 267-282.

World Health Organisation. (2006). Obstetric fistula: Guiding principle for clinical management and programme development. Geneva: WHO.

World Health Organisation. (2016). FGM Factsheet. Retrieved 24 ${ }^{\text {th }}$ March 2016 from: http://www.who.int/mediacentre/factsheets/fs241/en/

Wright, D., Woo, W., Muller, R., Fernandes, C., \& Kraftcheck, E. (2003). An investigation of trauma-centered inpatient treatment for adult survivors of abuse. Child Abuse and Neglect, 27(4), 393-406.

Yoder, P.S., Abderrahim, N, \& Zhuzhuni, A. (2004). Female genital cutting in the demographic and health surveys: a critical and comparative analysis. Calverton, Macro International 